\title{
Ventilatory Control in Infant Rats after Daily Episodes of Anoxia
}

\author{
CHIKAKO SAIKI AND JACOPO P. MORTOLA \\ Department of Physiology, McGill University, Montreal, Quebec, H3G 1Y6, Canada
}

\begin{abstract}
We asked whether the ventilatory control of the newborn rat was modified by preceding daily episodes of anoxia. At thermoneutrality (ambient temperature, $32^{\circ} \mathrm{C}$ ) during anoxia, respiratory efforts lasted, on average, 28,20 , and $11 \mathrm{~min}$ at 1,3 , and $7 \mathrm{~d}$, respectively. Therefore, we chose $10 \mathrm{~min}$ as the duration of a daily exposure to anoxia (100\% $N_{2}$ breathing) from $d 1$ to $d 6$ (experimental group). During the $7 \mathrm{~d}$ of the study, body growth was not different between the two groups. On d 7, respiratory measurements were performed and compared with those of rats never exposed to anoxia (controls). In normoxia, oxygen consumption $\left(\dot{\mathrm{VO}}_{2}\right.$, measured with an open-flow system) and ventilation (VE, measured by flow-plethysmography) were similar between control and experimental groups. Acute exposure to hypoxia (10 $\mathrm{min}$ of $10 \% \mathrm{O}_{2}$ ) resulted in a similar drop in $\mathrm{VO}_{2}$ and increase in $\dot{\mathrm{V}}_{\mathrm{E}}$ in both groups. During the last exposure to anoxia on d 7 , heart rate and breathing rate rapidly dropped; the attained degree of acidosis (blood $\mathrm{pH}$ and $\mathrm{PCO}_{2}$ ) was also similar to that of control rats. The results of the present experimental approach suggest that, in the newborn rat, daily episodes of anoxia during the 1st postnatal wk have no appreciable impact on body growth, ventilatory control, and the response to additional hypoxia. (Pediatr Res 35: 490-493, 1994)
\end{abstract}

\section{Abbreviations}

Tamb, ambient temperature

C, control group

$\mathbf{E}$, experimental group

$\dot{V}_{2}$, oxygen consumption

$\dot{V}_{E}$, ventilation

$\mathrm{F}_{10}$, inspired $\mathrm{O}_{2}$ concentration

The ability of the newborn mammal to sustain severe hypoxia, anoxia, or asphyxia has been known for many years; a brief hyperpneic response to oxygen lack is followed by apnea of variable duration, succeeded by gasping. If normoxia is restored before the last respiratory effort, the animal seemingly recovers by a process of autoresuscitation (1-4).

Whether the spontaneous restoration of breathing implies that the respiratory control mechanisms have fully recovered from the hypoxic event is likely to depend on the duration and severity of the episode. Breathing irregularities seem to be part of longterm neurologic sequelae in the most severe cases of perinatal hypoxia $(5,6)$. Prolonged hypoxia $\left(\mathrm{FIO}_{2}=10-12 \%\right)$ in the early

Received May 5, 1993; accepted November 24, 1993.

Correspondence: Dr. Jacopo P. Mortola, Department of Physiology, McGill University, 3655 Drummond St., Montreal, Quebec, H3G 1Y6 Canada.

C.S. was recipient of a bursary from the Nihon University, Tokyo, Japan. The study was supported by MRC Canada, and partly by funds from the Canadian Foundation for the Study of Infant Deaths and the Quebec Lung Association. postnatal period of the rat resulted in short- and long-term consequences on respiratory mechanics, regulation of breathing pattern, and other aspects of lung structure and function (7-12). However, the corresponding effects of severe but brief events of lack of oxygen are not known. In particular, because repetitive apneic spells or severe hypoxic episodes are not uncommon in the clinical setting, we were interested in examining to what extent brief anoxic incidents influence ventilatory control and the respiratory response to a following hypoxic episode.

In this study, we characterized the pattern of respiratory and cardiac activities during anoxia in rats at 1,3 , and $7 \mathrm{~d}$. On the basis of these results, a protocol of daily spells of anoxia has been applied to a second group of rats from $\mathrm{d} 1$ to $\mathrm{d} 6$. On $\mathrm{d} 7$, their normoxic ventilation and gaseous metabolism and the responses to hypoxia and anoxia were compared with those of control rats with no history of anoxic episodes.

\section{MATERIALS AND METHODS}

Experiments were conducted on conscious Sprague-Dawley rats observing experimental protocols approved by the animal care committee of this institution. At d 1 after birth, the smallest and heaviest of the litter were culled, which left a litter of 12 pups.

Protocol 1. Measurements were performed to characterize the response of the rat to anoxia in the 1st postnatal wk. The general protocol consisted in measuring heart and respiratory rates during normoxia and during anoxia at Tamb of $32^{\circ} \mathrm{C}\left( \pm 0.8^{\circ} \mathrm{C} \mathrm{SEM}\right)$, i.e. close to thermoneutrality (13). In an additional group of animals, the same measurements were performed at low Tamb $\left(24 \pm 0.4^{\circ} \mathrm{C}\right)$. At each age (d 1, 3, or 7 after birth), measurements were obtained from six to 15 pups of two to four litters. A separate group of 7-d-old rats $(n=11)$ was used for measurements of blood gases after 10 min of anoxia.

Protocol 2. A litter of pups was randomly assigned to $\mathrm{C}$ (two litters) or $\mathrm{E}$ group (two litters). The $\mathrm{E}$ pups were exposed to anoxia $\left(100 \% \mathrm{~N}_{2}\right)$ for $10 \mathrm{~min}$ each day, from $\mathrm{d} 1$ to $\mathrm{d} 6$ inclusive. Anoxic exposures were obtained by placing the pups in a 350$\mathrm{mL}$ chamber maintained at $32 \pm 1^{\circ} \mathrm{C}$. A flow of $\mathrm{N}_{2}$ (about 950 $\mathrm{mL} / \mathrm{min}$ ) was delivered through the chamber as the outflow gas concentration was monitored by an $\mathrm{O}_{2}$ analyzer. The duration of anoxia $(10 \mathrm{~min})$ was chosen on the basis of the results of protocol 1 (see Results). During this period, the $\mathrm{O}_{2}$ stores rapidly decrease and are almost completely depleted by the end of the exposure (Appendix). C pups were treated identically except that they were exposed daily to a flow of air in place of $\mathrm{N}_{2}$.

On $d 7$, recordings of breathing pattern and gaseous metabolism $\left(\dot{\mathrm{VO}}_{2}\right)$ during normoxia and acute hypoxia $\left(\mathrm{FIO}_{2}=10 \%\right)$ were obtained for 10 pups per group. In an additional group of 7 -d-old $\mathrm{E}$ rats $(n=10)$, blood gases were measured at $10 \mathrm{~min}$ of anoxia. The detailed breakdown of number of litters and animals used is provided in the Results section and figure legends.

Breathing and heart rates (protocol 1). Breathing efforts were monitored by airflow plethysmography, with a setup similar to that previously described $(15,16)$. In brief, the pup was prone in 
a 20-mL box with the head emerging through a double layer of paraffin sealing film (Parafilm). Box Tamb was monitored by a small thermal probe (model 400, Yellow Springs Instrument Co., Yellow Springs, $\mathrm{OH}$ ) and maintained by a large heating source around $32^{\circ} \mathrm{C}$, which corresponds to thermoneutrality (13). For some measurements of protocol 1 , Tamb was set at $24^{\circ} \mathrm{C}$ (cold). Airflow in the box was monitored by a small pneumotachograph connected to a differential pressure transducer. The front part of the plethysmograph was tightly connected to a second chamber, which was continuously flushed with the desired gas mixture (air or $100 \% \mathrm{~N}_{2}$ ) (16). The $\mathrm{O}_{2}$ concentration of the gas was continuously monitored by an $\mathrm{O}_{2}$ analyzer (model OM-15, Sensor Medics, Dayton, $\mathrm{OH}$ ).

ECG was measured by s.c. thread electrodes connected to a Grass amplifier (Grass Instrument Co., Quincy, MA). Airflow and ECG were recorded on paper (Gould pen recorder, Gould Inc., Cleveland, $\mathrm{OH}$ ) at a speed of $5 \mathrm{~mm} / \mathrm{s}$. Breathing rate and heart rate during anoxia were computed from the airflow signal and the ECG, respectively, every $2 \mathrm{~min}$ for the first $10 \mathrm{~min}$ of anoxia and every $4 \mathrm{~min}$ thereafter.

$\dot{V}_{E}$ and $\dot{V} O_{2}$ (protocol 2). The rat was placed in a doublechamber flow plethysmograph (16) similar to the setup used in protocol 1. The back chamber was used for measurements of breathing pattern by airflow plethysmography. The front chamber was used to measure $\mathrm{V}_{2}$ by an open-flow system (14). This chamber had an inlet and outlet for gas flow; gas flow was controlled by a flowmeter at $100 \mathrm{~mL} / \mathrm{min}$ volume of gas at standard temperature and pressure with no water vapor. The outflowing gas passed through a drying column (drierite) before being analyzed for fractional concentrations of $\mathrm{O}_{2}$ and $\mathrm{CO}_{2}$ by appropriate gas analyzers (Beckman OM-11 and Beckman LB2, Beckman Instruments, Fullerton, CA). These concentrations were displayed on a computer monitor after real-time acquisition. Inflowing dry gas concentrations could be checked at any time. After measurements in normoxia, gas inflow was switched to hypoxia $\left(10-30 \mathrm{~min}\right.$ of $\left.10 \% \mathrm{FIO}_{2}\right)$. $\mathrm{VO}_{2}$ was computed as the product between the gas flow and the inflow-outflow $\mathrm{O}_{2}$ concentration difference. Average difference between incurrent and excurrent gas concentrations was about $0.25-0.5 \%$; the accuracy of the analyzer was such that the measurement error was less than $2 \%$. Values of $\dot{\mathrm{VO}}_{2}$ are reported as volume of gas at standard temperature and pressure with no water vapor, normalized by the animal weight in kilograms.

Breathing pattern in normoxia and hypoxia was monitored simultaneously with $\mathrm{VO}_{2}$ and recorded on paper (two-channel Gould pen recorder, Gould Inc.). Two hundred breaths were digitized with the help of a graphics tablet connected to a minicomputer for computation of tidal volume (VT, $\mathrm{mL}$ ) and total cycle duration (TTOT, s), from which breathing frequency (f, breaths $/ \mathrm{min}=60 / \mathrm{TTOT}$ ) and minute ventilation ( $\dot{\mathrm{VE}}, \mathrm{mL}$ ) $\min =\mathrm{VT} \cdot \mathrm{f}$ ) were calculated.

Colonic temperature and blood gases. Colonic temperature was measured with a fine chromel/alumel thermocouple (Omega 871, Omega Engineering, Inc., Stamford, CT) and was interpreted as representative of body core temperature. Blood gases were sampled during anoxic exposure. After a few minutes of anoxia, none of the pups responded to touch or pain stimuli; hence, it was considered ethically acceptable to withdraw blood by percutaneous puncture of the heart at $10 \mathrm{~min}$ of anoxia. A $0.1-\mathrm{mL}$ sample was collected anaerobically and used for immediate blood gases determination (blood gas analyzer model 1302; Instrumentation Laboratory System, Lexington, MA); the values were corrected to the corresponding body core temperature of the animal (17).

Statistical analysis. Data are presented as means \pm 1 SEM. A significant difference between the average value of two sets of data was evaluated by two-way analysis of variance or two-way repeated measurement analysis of variance. Two-tailed $t$ test was performed on paired or unpaired data as appropriate. In all cases, a statistically significant difference was defined at $p<0.05$.

\section{RESULTS}

Response to anoxia at $d 1,3$, and 7 (protocol 1). Breathing and heart rates rapidly decreased at the onset of anoxia to very low values; then they increased slightly for a few minutes and then finally declined gradually toward zero (Fig. 1). The curves clearly differed according to postnatal age and Tamb. At thermoneutrality (open symbols), the last gasp and heart beat were after 28 and $45 \mathrm{~min}$ at $\mathrm{d} 1$ and only after 11 and $29 \mathrm{~min}$ at $\mathrm{d} 7$, respectively $(p<0.05)$. In the cold ( filled symbols), they were delayed in all age groups, although at $\mathrm{d} 7$ the difference did not meet our criteria of statistical significance. The times of the last breathing effort and heart beat significantly decreased with age, similar to what was observed at thermoneutrality. From these results, 10 min of anoxic exposure was considered the maximum duration that would allow survival of most pups of protocol 2 .

At the end of $10 \mathrm{~min}$ of anoxia, blood gases of 7-d-old rats

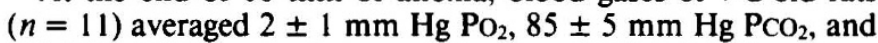
pH $6.88 \pm 0.02$; colonic temperature was $34.3 \pm 0.2^{\circ} \mathrm{C}$.

Effects of repeated anoxic episodes (protocol 2). Two of the 24 $\mathrm{E}$ pups died during anoxic exposure; both were $6 \mathrm{~d}$ old. Body growth of $\mathrm{E}$ pups was almost identical with that of $\mathrm{C}$ (Fig. 2). On d 7, no significant differences between $E$ and $C$ were seen in body weight (13.0 $\pm 0.3 \mathrm{~g}$ in $\mathrm{C}$ and $13.9 \pm 0.3 \mathrm{~g}$ in $\mathrm{E}), \dot{\mathrm{V}} \mathrm{O}_{2}, \dot{\mathrm{VE}}$, breathing pattern, or colonic temperature (Table 1 ).

On exposure to acute hypoxia, $\mathrm{VO}_{2}$ dropped in both $\mathrm{E}$ and $\mathrm{C}$ by a similar amount. Hypoxic $\dot{V}_{E}$ was slightly above the normoxic value because of an increase in respiratory rate; this change in breathing pattern was not significantly different between $\mathrm{C}$ and $E$ (Table 1).

On $\mathrm{d} 7$, an additional anoxic challenge in $\mathrm{E}(n=11)$ determined an immediate drop in respiratory and heart rates, which stopped by $12 \pm 1 \mathrm{~min}$ and $28 \pm 2 \mathrm{~min}$, respectively. At $10 \mathrm{~min}$ of anoxia, i.e. close to the time of the last gasp, blood $\mathrm{PO}_{2}$ averaged $(n=10) 2 \pm 1 \mathrm{~mm} \mathrm{Hg}, \mathrm{PCO}_{2} 81 \pm 5 \mathrm{~mm} \mathrm{Hg}$, and $\mathrm{pH}$ $6.93 \pm 0.02$; colonic temperature was $34.4 \pm 0.2^{\circ} \mathrm{C}$.

\section{DISCUSSION}

The extraordinary ability of the newborn mammal to survive with no $\mathrm{O}_{2}$ in the inspired air has long been known, and the dependence of anoxic resistance on postnatal age and temperature has also been well documented (18-21). The present study confirms these notions and indicates that in the rat anoxic resistance decreases rapidly during the 1 st postnatal wk. Breathing efforts in anoxia followed a bimodal pattern, as noted by Adolph $(1,20)$, similar to what occurs during asphyxia, in which the late rise in frequency corresponds to gasping activity (3). Hence, the present results of the 1 st protocol confirmed previous information and represented the basis for the 2 nd protocol, in which the duration of the anoxic episodes was fixed at $10 \mathrm{~min}$; this time corresponded to about one third of the gasping time at $\mathrm{d} 1$ and to almost the whole gasping period at $\mathrm{d} 7$, and it was tolerated by almost all pups. The two E pups that died (out of 24) did not survive the last anoxic exposure on $d 6$, which was in fact close to the maximum tolerable limit. Occurrence of apnea has been previously related to the severity of the hypoxia rather than the severity of the acidemia (22); the acidemia could further reduce brain metabolic rate (23), the low value of which is considered a key element for the ability of the developing brain to resist anoxia $(21,24)$.

The fact that body growth and metabolic rate of $E$ pups did not differ from $C$ are suggestive indications that no major body function was seriously compromised by the repeated anoxia. The normality in body growth is a finding that agrees with previous observations in rat pups exposed to severe episodes of asphyxia or hypoxia $(25,26)$. Some of the infants who survived severe asphyxia at birth presented apparently normal body and neurologic development by 3-7 y of age $(27,28)$.

The question that we proposed at the onset was to what extent daily occurrence of an anoxic spell may affect the regulation of 


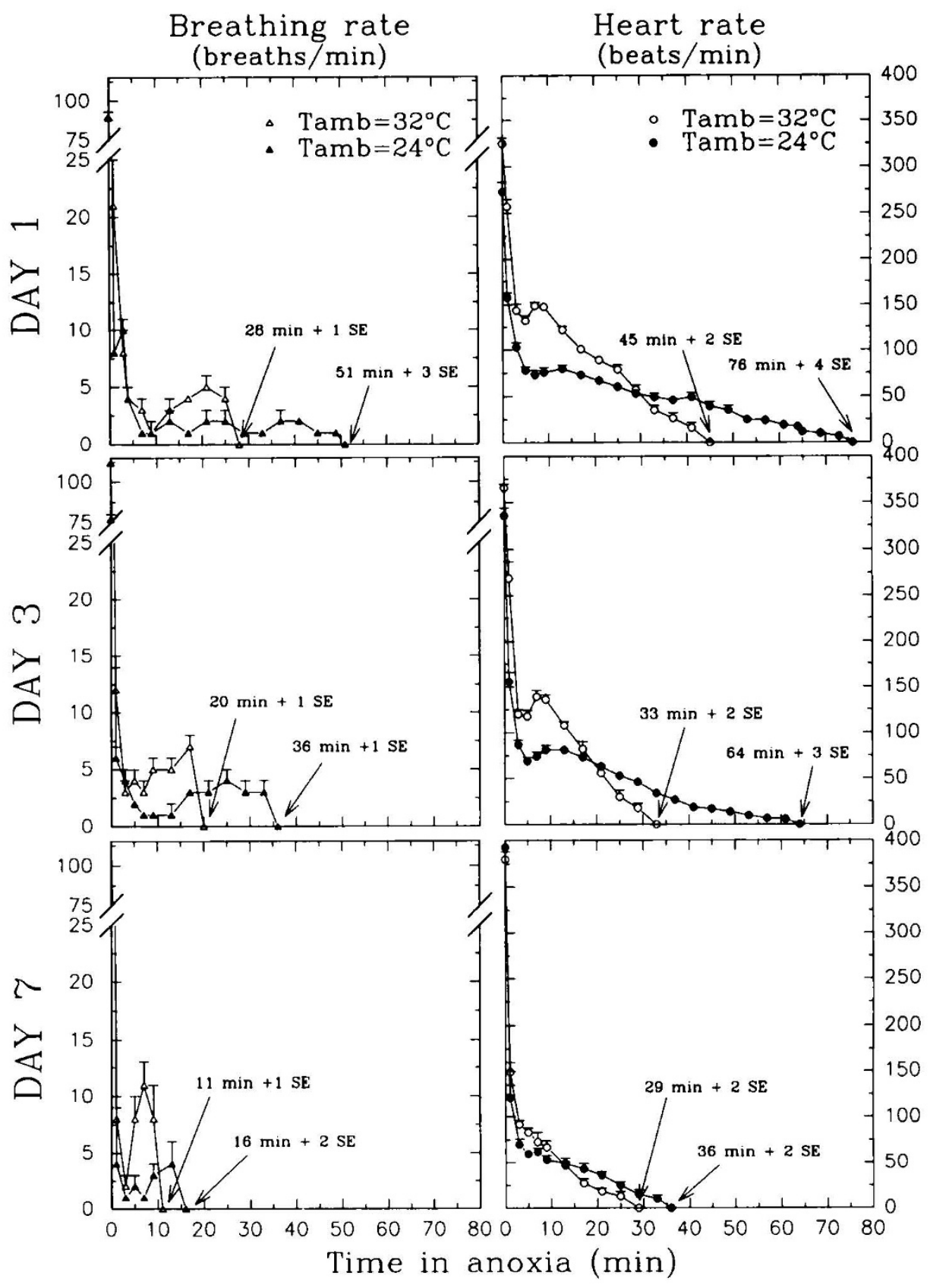

Fig. 1. Time course of breathing rate $(l e f t)$ and heart rate (right) during anoxia in rats of 1,3 , and $7 \mathrm{~d}$ of age at thermoneutrality $\left(32 \pm 0.8^{\circ} \mathrm{C}\right.$, open symbols $)$ and in cold $\left(24 \pm 0.4^{\circ} \mathrm{C}\right.$, filled symbols $)$. Symbols are group means; bars represent 1 SEM. Average times of the last gasp and heart beat are indicated. Number of animals in each group ranged between 6 and 15 from two to four litters.

breathing, an aspect not previously examined and yet important in the response to additional hypoxic or anoxic episodes. No differences in breathing pattern or metabolic rate were observed between $\mathrm{C}$ and $\mathrm{E}$ whether in normoxia or in hypoxia. In the 7d-old $E$ pups, duration of gasping and heart activities, and blood gases and body core temperature by the end of anoxia were also similar to those of untreated 7-d-old rats, indicating comparable metabolic adjustments during anoxia. Therefore, we conclude that daily anoxic episodes have no measurable effects on respiratory control.

The above conclusion, however, is limited by the characteristics of our experimental design. In particular, we did not consider other aspects of respiratory regulation, including the response to acute hypercapnia and its interaction with hypoxia, which may have revealed some differences in ventilatory control between $\mathrm{C}$ and $\mathrm{E}$. Clinical anoxic episodes, either determined by prolonged periods of apnea or airway obstruction, are accompanied by rapid $\mathrm{CO}_{2}$ retention and acidosis; we have chosen to induce anoxia via $\mathrm{N}_{2}$ breathing, therefore delaying the acidosis, which could have more readily compromised neuronal function. Hypothermia, which protects neonates from asphyxia (19) and greatly prolongs respiratory and cardiac activities in anoxia (Fig. 1), is likely to enhance further the tolerance to repeated anoxia. Finally, we cannot exclude that an even higher frequency of anoxic spells may have resulted in some alterations of respiratory control. In this respect, it was previously observed in the rat that moderate but continuous hypoxia during the 1st postnatal wk reduced body growth and resulted in numerous long-lasting alterations of the respiratory function, including aspects of ventilatory control $(7,8,10)$.

In conclusion, the present results indicate that newborn rats can tolerate daily anoxic spells remarkably well, with no major effects on respiratory control. 


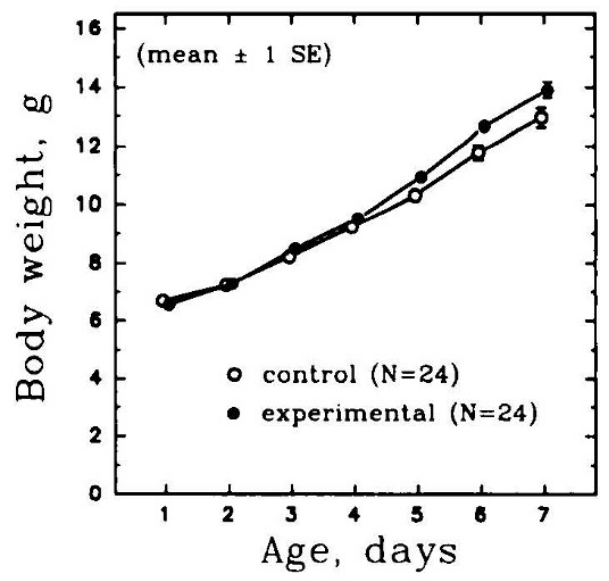

Fig. 2. Body weights during the 1st postnatal wk in control (open symbols) and experimental rats (filled symbols). Symbols are means of 24 control and 24 experimental rats, each from two litters. Bars indicate 1 SEM; when not represented, SEM was within the size of the symbol. At no age did the values of the two groups significantly differ from each other.

Table 1. Values in normoxia and acute hypoxia in 7-d-old rats*

\begin{tabular}{lccc}
\hline & $\begin{array}{c}\mathrm{FiO}_{2} \\
(\%)\end{array}$ & $\mathrm{C}$ & $\mathrm{E}$ \\
\hline $\mathrm{No}$ of animals & & 10 & 10 \\
$\dot{\mathrm{V}} \mathrm{O}_{2}\left(\mathrm{~mL} \cdot \mathrm{kg}^{-1} \cdot \mathrm{min}^{-1}\right)$ & 21 & $34 \pm 1$ & $37 \pm 1$ \\
& 10 & $18 \pm 1 \dagger$ & $20 \pm 1 \dagger$ \\
$\dot{\mathrm{VE}}\left(\mathrm{mL} \cdot \mathrm{kg}^{-1} \cdot \mathrm{min}^{-1}\right)$ & 21 & $1098 \pm 55$ & $1138 \pm 27$ \\
& 10 & $1392 \pm 52 \dagger$ & $1445 \pm 71 \dagger$ \\
$\mathrm{VT}\left(\mathrm{mL} \cdot \mathbf{k g}^{-1}\right)$ & 21 & $7.9 \pm 0.4$ & $7.9 \pm 0.3$ \\
& 10 & $8.1 \pm 0.4$ & $7.6 \pm 0.4$ \\
Frequency (breaths/min) & 21 & $141 \pm 4$ & $148 \pm 4$ \\
& 10 & $177 \pm 9 \dagger$ & $194 \pm 5 \dagger$ \\
$\dot{\mathrm{V}} / \dot{V}_{2}$ & 21 & $33 \pm 1$ & $31 \pm 1$ \\
& 10 & $79 \pm 4 \dagger$ & $74 \pm 5 \dagger$ \\
Colonic temperature ("C) & 21 & $35.1 \pm 0.3$ & $35.5 \pm 0.3$ \\
& 10 & $34.4 \pm 0.2$ & $34.6 \pm 0.3 \dagger$ \\
\hline
\end{tabular}

- Values are group mean \pm 1 SEM. None of the experimental values differed significantly from control. VT, tidal volume.

+ Significant difference from $21 \%$.

Acknowledgment. The authors thank Lina Naso for technical assistance.

\section{REFERENCES}

1. Adolph EF 1969 Regulations during survival without oxygen in infant mammals. Respir Physiol 7:356-368

2. Guntheroth WG 1974 Primary apnea, hypoxic apnea and gasping. In: Robinson RR (ed) SIDS. The Canadian Foundation for the Study of Infant Deaths, Toronto, pp. 243-247

3. Thach BT, Jacobi MS, Gershan WM 1991 Control of breathing during asphyxia and autoresuscitation. In: Haddad GG, Farber JP (eds) Developmental Neurobiology of Breathing, Lung Biology in Health and Disease Series, Vol 53. Dekker, New York, pp 681-699

4. Mott JC 1961 The ability of young mammals to withstand total oxygen lack. Br Med Bull 17:144-148

5. Mulligan JC, Painter MJ, O'Donoghue PA, MacDonald HM, Allen AC, Taylor PM 1980 Neonatal asphyxia. II. Neonatal mortality and long-term sequelae. J Pediatr 96:903-907

6. Trojan S, Stastný F 1988 Hypoxia and the developing brain. In: Meisami E, Timiras PS (eds) Handbook of Human Growth and Developmental Biology, Vol I: Neural, Sensory, Motor, and Integrative Development, Part C. CRC Press, Boca Raton, FL, pp 101-123

7. Eden GJ, Hanson MA 1987 Effects of chronic hypoxia from birth on the ventilatory response to acute hypoxia in the newborn rat. J Physiol (Lond) 392:11-19

8. Okubo S, Mortola JP 1988 Long-term respiratory effects of neonatal hypoxia in the rat. J Appl Physiol 64:952-958

9. Okubo S, Mortola JP 1989 Respiratory mechanics in adult rats hypoxic in the neonatal period. J Appl Physiol 66:1772-1778

10. Okubo S, Mortola JP 1990 Control of ventilation in adult rats hypoxic in the neonatal period. Am J Physiol 259:R836-R841

11. Hakim TS, Mortola JP 1990 Pulmonary vascular resistance in adult rats exposed to hypoxia in the neonatal period. Can J Physiol Pharmacol 68:419424

12. Massaro GD, Olivier J, Massaro D 1989 Short-term perinatal $10 \% \mathrm{O}_{2}$ alters postnatal development of lung alveoli. Am J Physiol 257:L221-L225

13. Mortola JP, Dotta A 1992 Effects of hypoxia and ambient temperature on gaseous metabolism of newborn rats. Am J Physiol 263:R267-R272

14. Frappell P, Saiki C, Mortola JP 1991 Metabolism during normoxia, hypoxia and recovery in the newborn kitten. Respir Physiol 86:115-124

15. Mortola JP 1984 Breathing pattern in newborns. J Appl Physiol 56:1533-1540

16. Saetta M, Mortola JP 1985 Breathing pattern and $\mathrm{CO}_{2}$ response in newborn rats before and during anesthesia. J Appl Physiol 58:1988-1996

17. Severinghaus JW 1966 Blood gas calculator. J Appl Physiol 21:1108-1116

18. Glass HG, Snyder FF, Webster E 1944 The rate of decline in resistance to anoxia of rabbits, dogs and guinea pigs from the onset of viability to adult life. Am J Physiol 140:609-615

19. Miller Jr JA, Miller FS, Westin B 1964 Hypothermia in the treatment of asphyxia neonatorum. Biol Neonate 6:148-163

20. Adolph EF 1973 Physiological adaptations in hypoxia in infant mammals. Am Zool 13:469-473

21. Duffy TE, Kohle SJ, Vannucci RC 1975 Carbohydrate and energy metabolism in perinatal rat brain: relation to survival in anoxia. J Neurochem 24:271276

22. Guntheroth WG, Kawabori 11975 Hypoxic apnea and gasping. J Clin Invest 56:1371-1377

23. Vannucci RC, Duffy TE 1976 Carbohydrate metabolism in fetal and neonatal rat brain during anoxia and recovery. Am J Physiol 230:1269-1275

24. Duffy TE, Vannucci RC 1977 Metabolic aspects of cerebral anoxia in the fetus and newborn. In: Berenberg SR (ed) Brain, Fetal and Infant. Martinus Nijhoff Medical Division, The Hague, pp 316-323

25. Trojan S, Jilek L 1964 The consequences of repeated exposure to stagnation anoxia during early postnatal development of the rat. Physiol Bohemoslov 13:473-477

26. Ferrara A, Atakent Y, Bhogal M, Klupsteen M 1984 Impact of intermittent prolonged asphyxia in rat sucklings on growth and development. Growth 48:120-133

27. Fraser MS, Wilks J 1959 The residual effects of neonatal asphyxia. J Obstet Gynaecol Br Emp 66:748-752

28. Scott H 1976 Outcome of very severe birth asphyxia. Arch Dis Child 51:712716

\section{APPENDIX}

\section{BODY $\mathrm{O}_{2}$ STORE IN A 6-G NEWBORN RAT}

Blood. Total volume $=100 \mathrm{~mL} / \mathrm{kg} . \mathrm{Hb}=0.09 \mathrm{~g} / \mathrm{mL}$ blood, each binding $1.34 \mathrm{~mL}$ of $\mathrm{O}_{2}$, with $100 \%$ desaturation. Blood $\mathrm{O}_{2}$ $(\mathrm{mL})=0.006 \mathrm{~kg} \cdot 100 \mathrm{~mL} / \mathrm{kg} \cdot 0.09 \mathrm{~g} \mathrm{Hb} / \mathrm{mL} \cdot 1.34 \mathrm{~mL} \mathrm{O} / \mathrm{g} \mathrm{Hb}$ $=0.07$. If arterial and venous blood (one fourth and three fourths of total) maximal desaturation were only $50 \%$ and $90 \%$ of the maximal $\mathrm{O}_{2}$ capacity, respectively, blood effective $\mathrm{O}_{2}$ stores would be about $0.06 \mathrm{~mL}$.

Muscle. Skeletal muscle mass $=$ one third of body mass. Muscle myoglobin $(\mathrm{Mb})=45 \mathrm{~g} / \mathrm{kg}$ muscle, each binding 1.34 $\mathrm{mL} \mathrm{O}$, with $100 \%$ desaturation. Muscle $\mathrm{O}_{2}(\mathrm{~mL})=0.006 \mathrm{~kg}$. $0.33 .45 \mathrm{~g} \mathrm{Mb} / \mathrm{kg} \cdot 1.34 \mathrm{~mL} \mathrm{O} / \mathrm{g} \mathrm{Mb}=0.12$.

Lungs. Functional residual capacity $=50 \mathrm{~mL} / \mathrm{kg}$ of air $(0.21 \%$ $\mathrm{O}_{2}$ ): Lung $\mathrm{O}_{2}(\mathrm{~mL})=0.006 \mathrm{~kg} \cdot 50 \mathrm{~mL} / \mathrm{kg} \cdot 0.21=0.063$.

Total $\mathrm{O}_{2}$ stores (blood + muscles + lungs) $=0.07+0.12+$ $0.06=0.25 \mathrm{~mL}$ at body temperature and ambient pressure and saturated with water vapor, or $42 \mathrm{~mL} / \mathrm{kg}$.

During $\mathrm{N}_{2}$ breathing, the $\mathrm{O}_{2}$ in the lung is eliminated within a few breaths. If the newborn's aerobic metabolism remained around the normoxic value [about $40 \mathrm{~mL} \cdot \mathrm{kg}^{-1} \cdot \mathrm{min}^{-1}(13)$ ] the whole-body $\mathrm{O}_{2}$ stores would be entirely depleted in less than 1 $\mathrm{min}$. The rate of depletion is slower because of the rapid drop in $\mathrm{VO}_{2}$ at the onset of hypoxia (14) but probably completed after $10 \mathrm{~min}$ of anoxia, when arterial $\mathrm{PO}_{2}$ averaged $2 \mathrm{~mm} \mathrm{Hg}$. 